\title{
Nocturnal low-level clouds over southern West Africa analysed using high-resolution simulations
}

\author{
Bianca Adler, Norbert Kalthoff, and Leonhard Gantner \\ Institute of Meteorology and Climate Research, Karlsruhe Institute of Technology (KIT), Karlsruhe, Germany \\ Correspondence to: Bianca Adler (bianca.adler@kit.edu)
}

Received: 21 September 2016 - Published in Atmos. Chem. Phys. Discuss.: 11 October 2016

Revised: 3 January 2017 - Accepted: 4 January 2017 - Published: 20 January 2017

\begin{abstract}
We performed a high-resolution numerical simulation to study the development of extensive low-level clouds that frequently form over southern West Africa during the monsoon season. This study was made in preparation for a field campaign in 2016 within the Dynamicsaerosol-chemistry-cloud interactions in West Africa (DACCIWA) project and focuses on an area around the city of Savè in southern Benin. Nocturnal low-level clouds evolve a few hundred metres above the ground around the same level as a distinct low-level jet. Several processes are found to determine the spatio-temporal evolution of these clouds including (i) significant cooling of the nocturnal atmosphere caused by horizontal advection with the south-westerly monsoon flow during the first half of the night, (ii) vertical cold air advection due to gravity waves leading to clouds in the wave crests and (iii) enhanced convergence and upward motion upstream of existing clouds that trigger new clouds. The latter is caused by an upward shift of the low-level jet in cloudy areas leading to horizontal convergence in the lower part and to horizontal divergence in the upper part of the cloud layer. Although this single case study hardly allows for a generalisation of the processes found, the results added to the optimisation of the measurements strategy for the field campaign and the observations will be used to test the hypotheses for cloud formation resulting from this study.
\end{abstract}

\section{Introduction}

During the West African monsoon season, nocturnal lowlevel stratiform clouds frequently form over southern West Africa with a cloud base of only few hundred metres above ground (Schrage and Fink, 2012; Schuster et al., 2013; van der Linden et al., 2015). From synoptic observations and various satellite products van der Linden et al. (2015) derived a climatology of low-level clouds over southern West Africa for the monsoon seasons from 2006 to 2011 . The affected area covers approximately $800000 \mathrm{~km}^{2}$. Low-level clouds frequently form shortly after sunset along the coast and upstream of the Mampong Range in Ghana and the Oshogbo Hills in Nigeria and spread during the night (Schuster et al., 2013; van der Linden et al., 2015). As these clouds persist into the late morning or early afternoon, they reduce surface solar radiation and could strongly affect the regional heat and moisture budgets and, thus, the West African climate (Knippertz et al., 2011).

The mechanisms controlling the formation and maintenance of the low-level clouds were investigated by Schrage and Fink (2012), using observations at Nangatchori (Benin, $9.70^{\circ} \mathrm{N}, 1.68^{\circ} \mathrm{E} ; 434 \mathrm{~m}$ above mean sea level, m.s.l.) and by Schuster et al. (2013), who simulated the 2006 monsoon season and analysed atmospheric conditions averaged for clear and cloudy nights. Based on these few studies, current theories relating to low-level cloud formation suggest that these clouds evolve in connection with a nocturnal south-westerly low-level jet (LLJ), which forms regularly in this region and is linked to the Saharan heat low (e.g. Parker et al., 2005; Lothon et al., 2008; Abdou et al., 2010). The jet axis is several hundred metres above ground, i.e. generally around the same level as the low-level clouds. In the simulations of Schuster et al. (2013), the LLJ is on average several $\mathrm{m} \mathrm{s}^{-1}$ stronger during cloudy nights than during clear nights. They propose that the relevance of different processes to low-level cloud formation varies depending on the region. While sheargenerated turbulent vertical mixing of moisture underneath the LLJ is a main process close to the coast, orographically 
induced lifting upstream of higher terrain is more important farther inland. In both regions, horizontal cold air advection is strong in and underneath the LLJ layer, and radiative cooling at the cloud top helps to maintain the low-level clouds once they have formed. Schrage and Fink (2012) proposed that vertical mixing of moisture due to shear-generated turbulence underneath the LLJ is the major process for cloud formation far inland at Nangatchori. However, no answers were given to the questions why many nights with an LLJ remain clear and why the LLJ does not form during some nights with low-level clouds.

The existing studies suggest that a lot of effort is still needed to identify controls of the development of the lowlevel clouds and to improve the understanding of the involved physical processes. In particular, there is a large demand for high-quality observations in this region for process studies and model validation. To meet this demand, a field campaign was conducted in the 2016 monsoon season in southern West Africa within the framework of the Dynamics-aerosolchemistry-cloud interactions in West Africa (DACCIWA) project (Knippertz et al., 2015a). In the regions favourable for low-level clouds (van der Linden et al., 2015), three supersites were installed at Kumasi (Ghana), Savè (Benin) and Ile-Ife (Nigeria).

In preparation for this field campaign, we performed highresolution simulations with the Consortium for Small-Scale Modeling (COSMO) model for the area around the supersite at Savè $\left(8.00^{\circ} \mathrm{N}, 2.43^{\circ} \mathrm{E} ; 166 \mathrm{~m} \mathrm{~m}\right.$.s.l. $)$, i.e. about $200 \mathrm{~km}$ inland from the Guinea Coast (Fig. 1). At this supersite, various remote sensing and in situ systems, including the KITcube mobile observation platform (Kalthoff et al., 2013), were operated during the field campaign. This study aims at identifying possible controls of the development of the nocturnal low-level clouds in the simulation. These results were then used to optimise the measurement strategy for the field campaign. Contrary to Schuster et al. (2013), who simulated a large part of southern West Africa for the whole monsoon season of 2006, we performed a case study for a smaller domain around the supersite at Savè with a significantly higher horizontal and vertical resolution. This set-up was chosen to resolve the vertical structure of the nocturnal boundary layer and the LLJ as well as small-scale processes possibly relevant to the low-level clouds.

The paper is structured as follows: the next section covers the model set-up, followed by a description of the simulated evolution of low-level clouds in Sect. 3. In Sect. 4, we analyse the atmospheric conditions and processes relevant to low-level clouds for different phases of the night. Section 5 presents a discussion and Sect. 6 provides a summary and conclusions.

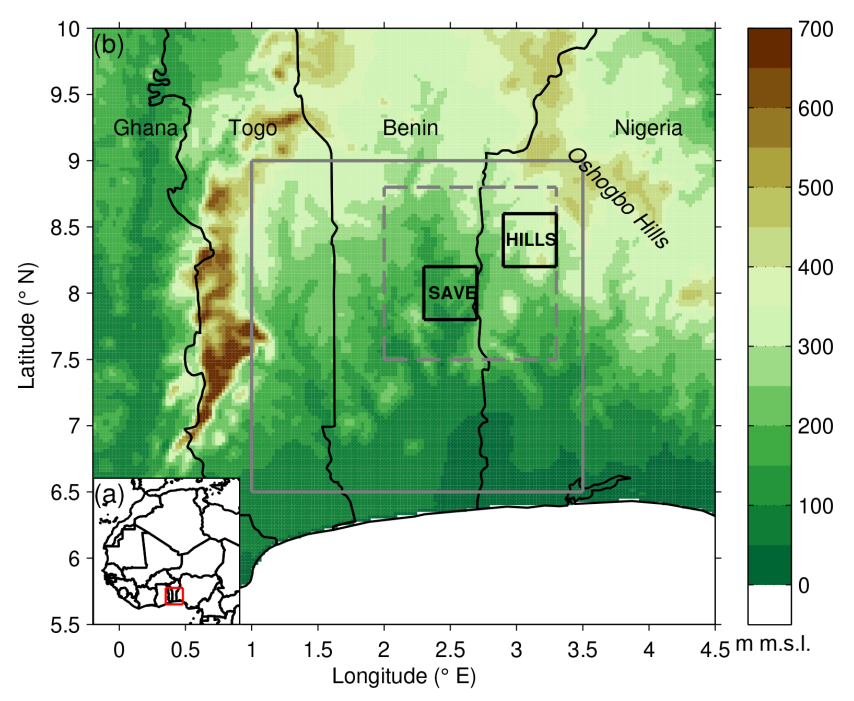

Figure 1. Location of the area of interest (red box) in West Africa (a) and orography of the area of interest in southern West Africa (b). The model domain and the area used for the analysis are indicated by the boxes with the solid grey and dashed grey lines, respectively, and the SAVE and HILLS boxes show the areas used for detailed investigation. The city of Savè is located in the centre of SAVE.

\section{Model set-up}

For this study, we use the COSMO model, version 5.1, which is a fully compressible non-hydrostatic regional weather forecast model (Schättler et al., 2014) used for operational weather forecasting as well as for scientific applications down to high resolutions. The model run was performed with a horizontal grid spacing of around $500 \mathrm{~m}\left(0.005^{\circ}\right)$ and a hybrid system with 80 layers up to $22 \mathrm{~km}$ with 33 layers below $1.8 \mathrm{~km}$. COSMO model simulations with similar high horizontal resolution have been performed by Fiori et al. (2010) to study deep moist convection and by Gantner et al. (2016) to investigate the cloud-topped boundary layer. For comparison, Schuster et al. (2013) used a horizontal grid spacing of $3 \mathrm{~km}$ and 70 vertical layers, of which 20 were below $1.8 \mathrm{~km}$. The horizontal differencing in the COSMO model is done on a latitude-longitude grid using an Arakawa C-grid and a generalised terrain-following height coordinate is implemented in vertical direction. For turbulent diffusion, we use a 3-D turbulence parameterisation based on the extended Smagorinsky model according to Herzog et al. (2002) and also applied by Fiori et al. (2010) and Gantner et al. (2016). In this parameterisation, turbulence diffusion coefficients depend on horizontal and vertical grid size, stability and turbulent kinetic energy, which is retrieved from a prognostic equation. Due to the high horizontal resolution, the model is convection resolving and therefore convection parameterisation is turned off in this simulation. At lower horizontal resolutions, sub-grid-scale clouds are considered in the ra- 
diation scheme after Ritter and Geleyn (1992), by applying either a relative humidity criterion or a statistical criterion. However, the consideration of sub-grid-scale clouds is highly uncertain at such high horizontal resolution as chosen in this study and it is not clear whether the criteria are applicable or not (Boutle et al., 2016). We performed sensitivity tests for the region in West Africa and found that the consideration of sub-grid-scale clouds in the radiation scheme delays the transition from stratiform clouds to convective clouds by several hours, while the impact on the qualitative characteristics of the nocturnal low-level clouds is small. For the simulation analysed in this study, we decided to consider only grid-scale clouds in the radiation scheme, which is called every $15 \mathrm{~min}$. Whether this choice leads to more realistic results or not, could be investigated in upcoming studies using observations from the DACCIWA field campaign. Using an online trajectory module implemented in COSMO (Miltenberger et al., 2013), trajectories are started hourly at $7.5^{\circ} \mathrm{N}$ between 1.5 and $2.5^{\circ} \mathrm{E}$ at various levels below $2000 \mathrm{~m}$ m.s.l. in order to obtain information on the origin of air parcels, which are involved in the evolution of the low-level clouds.

For initialisation and boundary conditions of the atmospheric part of the model, a convection-resolving simulation with $2.8 \mathrm{~km}$ horizontal grid spacing performed with the COSMO model for the northern half of Africa for the whole year of 2006 (Maurer et al., 2016) is used. An advantage of using this simulation is that the lower boundary, particularly the soil moisture, is tuned and long spin-up times are unnecessary. As the $2.8 \mathrm{~km}$ simulation is initialised on 1 January 2006 and the model domain is very large (about $2500 \times 1800$ grid points); the simulated atmospheric conditions on a specific day do not necessarily agree with the observations. However, the overall characteristics of the simulated data are realistic and precipitation statistics match well with Tropical Rainfall Measuring Mission (TRMM) data (Maurer et al., 2016).

We examine the $2.8 \mathrm{~km}$ simulation for periods during the monsoon season when the conditions in the area of interest are characterised by conditions assumed to be favourable for the evolution of low-level clouds (Schrage and Fink, 2012). This means we are looking for periods with a southwesterly monsoon flow, a strong nocturnal LLJ and high relative humidity at low levels, which are free of disturbances by large-scale events such as mesoscale convective systems and free of precipitation. Of these periods, we choose a night at the beginning of August for analysis. The simulation is initialised at 12:00 UTC and runs for $30 \mathrm{~h}$ with the boundary conditions being updated every hour. For the analysis, we use 15 min model output on $z$ levels and times are given in UTC, the local standard time in Benin being UTC plus $1 \mathrm{~h}$. The model domain ranges from 6.5 to $9^{\circ} \mathrm{N}$ and 1 to $3.5^{\circ} \mathrm{E}$ and contains $501 \times 511$ grid points (Fig. 1). To prevent boundary effects, the analysis is confined to a smaller area with about $100 \mathrm{~km}$ distance to the upstream (southern and western) boundaries. In the area used for the analysis, the ter- rain gradually increases from south to north, with Savè being about $100 \mathrm{~km}$ south-west, i.e. upstream, of the Oshogbo Hills, which rise up to $500 \mathrm{~mm}$.s.l. To assess the impact of different terrain heights on the low-level clouds, we investigate two areas of $40 \mathrm{~km} \times 40 \mathrm{~km}$ in detail: the SAVE area, which is centred on the location of the supersite at Savè, is characterised by a mean terrain height of $156 \mathrm{~mm}$.s.l., and the HILLS area is directly upstream of the peaks of the Oshogbo Hills with a mean terrain height of $322 \mathrm{~m}$ m.s.l.

\section{Evolution of low-level clouds}

To obtain information about the spatial distribution and temporal evolution of low-level clouds, we accumulate the liquid water content up to $1200 \mathrm{~mm}$.s.l., i.e. up to the top of the domain-averaged low-level clouds, (Fig. 2a, b) and average profiles of the liquid water content for both areas SAVE (Fig. 2c) and HILLS (Fig. 2d). Throughout the night, the horizontal and vertical extent as well as the liquid water content of the low-level clouds vary, allowing us to distinguish different phases. In the following, we use the term density to distinguish between clouds with low and high liquid water content.

Before about 22:00 UTC, the analysed area is free of lowlevel clouds (phase 0). First low-level clouds form after around 22:00 UTC in HILLS and after midnight in SAVE (phase 1, Fig. 2c, d). During this phase, the low-level clouds are denser and more extended over the higher terrain in the north-eastern part of the analysed area (Fig. 2a). In the other parts of the area, clouds remain rather patchy and less dense. After 03:00 UTC, dense low-level clouds spread towards the south-west, thus, increasing the liquid water content in SAVE (phase 2, Fig. 2b, c). After around 05:00 UTC, the dense clouds withdraw somewhat to the north-east, causing the averaged liquid water content in SAVE to decrease (Fig. 2c). During this phase, the clouds in HILLS have a higher density and a larger vertical extent than during phase 1 (Fig. 2d). Considering the different terrain heights, cloudbase heights above sea level are remarkably similar in both areas (Fig. 2c, d). With the onset of surface heating, the cloud base rises after 08:00 UTC and convective clouds form.

\section{Atmospheric conditions and processes relevant to low-level clouds}

The differences in the temporal and spatial evolution of clouds in SAVE and HILLS suggest that different processes are relevant in the two areas. To understand the evolution of low-level clouds, we analyse in detail the atmospheric conditions and the processes such as advection, which affect these conditions during the different phases. For this purpose, we calculate tendencies of potential temperature and moisture from the $15 \mathrm{~min}$ model output and average them for the SAVE (Fig. 3) and HILLS areas (not shown). When us- 


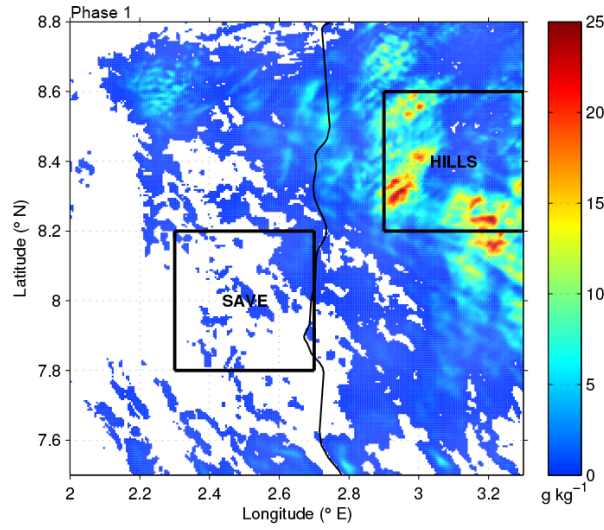

(a)

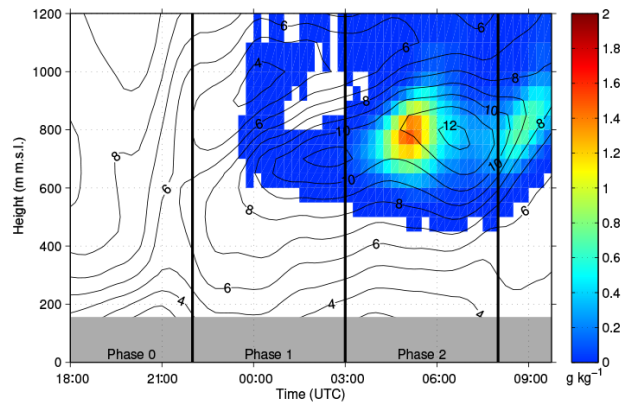

(c)

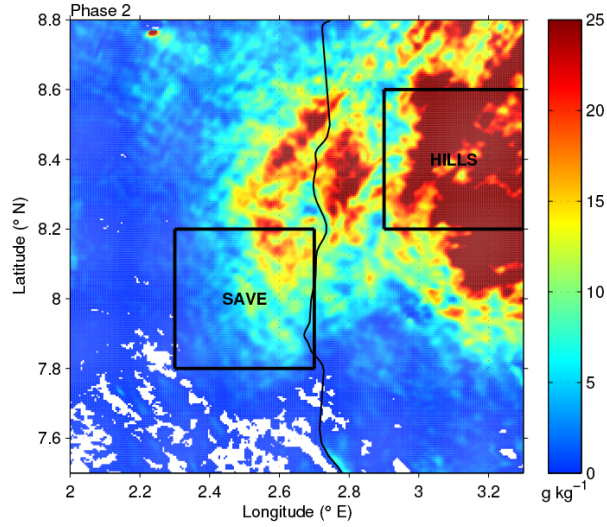

(b)

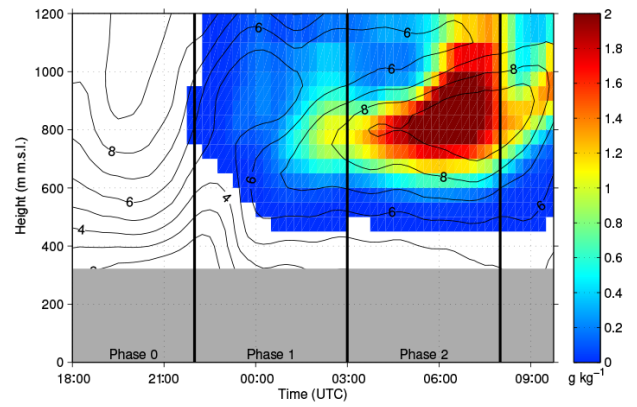

(d)

Figure 2. Spatial distribution of the liquid water content accumulated below $1200 \mathrm{~mm} . \mathrm{s} .1$. averaged between 22:00 and 03:00 UTC (a) phase 1) and between 03:00 and 08:00 UTC (b; phase 2) and temporal evolution of the liquid water content (colour-coded) and horizontal wind in $\mathrm{m} \mathrm{s}^{-1}$ (black contours) profiles averaged for SAVE (c) and HILLS (d). Grey shaded areas in (c) and (d) mark the mean terrain height.

ing the term moisture, we are referring to specific humidity. To study contributions to the tendencies by advection, we determine horizontal and vertical advection for each grid point and each level and average over the area. Note that parts of the contributions by advection result from inclined isentropes and isohumes over the smoothly sloping terrain. As contributions of sub-grid-scale mixing, divergence of net radiation or phase changes to the tendencies cannot be quantified in the simulation due to unavailable output, residuals result. The residuals are determined by simply subtracting the advection terms from the tendencies (Fig. 3d, h). Although the residuals are influenced by subtracting the instantaneous advection terms from the tendencies calculated from the 15 min output, the magnitude and sign of the residuals provide some qualitative information: for example, the residual for the heat budget is found to be very large near the surface during phase 0 when a nocturnal inversion evolves due to surface cooling (negative sensible surface heat flux) and in the morning when the convective boundary layer forms due to heating of the surface (positive sensible surface heat flux). During phases 1 and 2, the budgets are dominated by the contributions of the advection terms.

\subsection{Before the onset of low-level clouds (phase 0)}

The evolution of the stably stratified nocturnal boundary layer is significantly influenced by strong cooling and moistening in the first half of the night (shown for SAVE in Fig. 3a, e), leading to a rapid increase of relative humidity throughout the lower atmosphere (shown for SAVE in Fig. 4).

Most of the cooling and moistening occurs between 20:30 and 23:00 UTC in SAVE (Fig. 3a, e) and between 21:00 and 23:00 UTC in HILLS (not shown). Due to box averaging, cooling and moistening appears to be rather smooth. The analysis of spatial distributions of atmospheric variables (not shown), however, reveals that the temperature and humidity changes are associated with a cool and moist air mass, which propagates northwards showing a front-like, sharp, roughly west-east oriented boundary on its leading edge. Behind the front, relative humidity increases to more than $90 \%$ (Fig. 4), making the atmosphere favourable for the formation of clouds.

As the front seems to play an important role for the formation of the low-level clouds, we investigate the $2.8 \mathrm{~km}$ simulation during the months of July and August 2006 for 

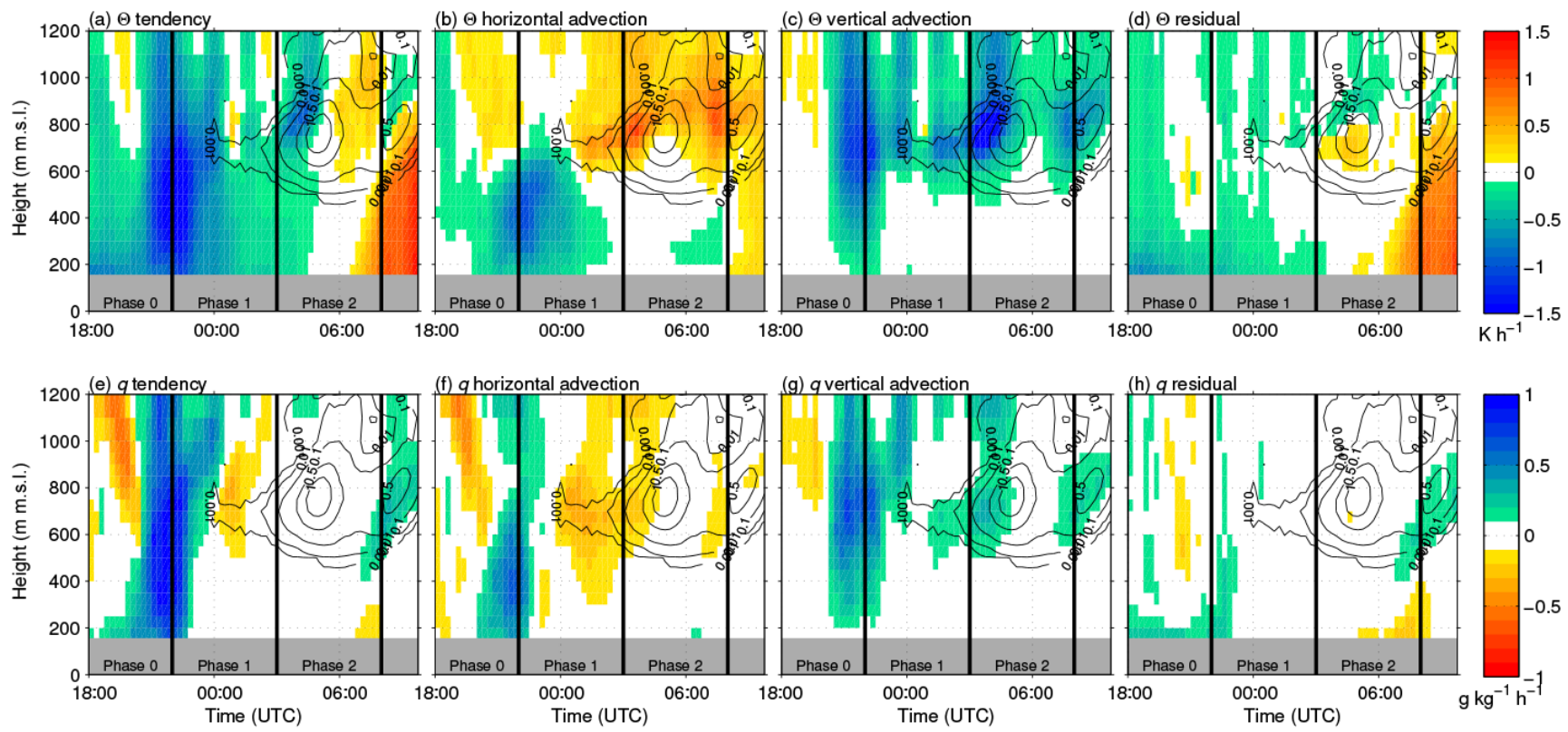

Figure 3. Temporal evolution of tendencies and of contributions to tendencies by horizontal advection and vertical advection for potential temperature (a-c) and moisture (specific humidity; e-g) averaged for SAVE. The residuals are determined by subtracting the contributions by advection from the tendencies $(\mathbf{d}, \mathbf{h})$. Liquid water content in $\mathrm{g} \mathrm{kg}^{-1}$ is indicated by the black contours. Grey shaded areas mark the mean terrain height.

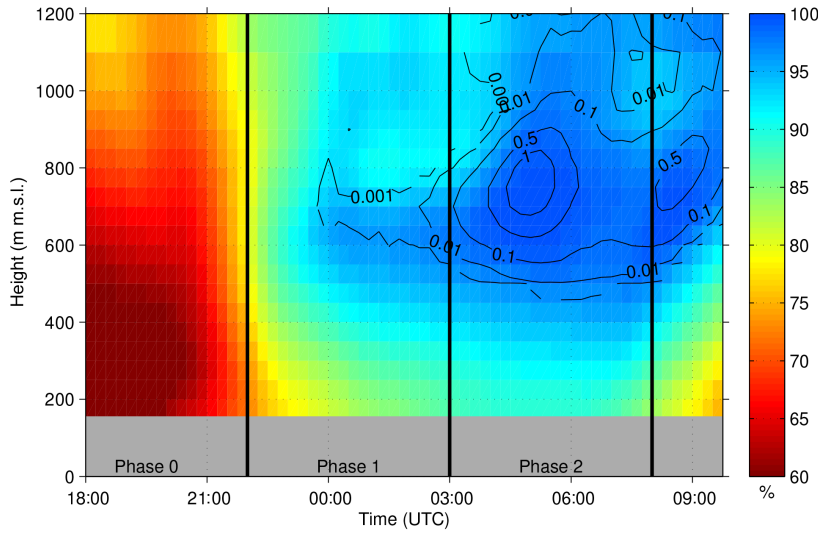

Figure 4. Temporal evolution of relative humidity (colour-coded) and liquid water content in $\mathrm{g} \mathrm{kg}^{-1}$ (black contours) averaged for SAVE. The grey shaded area marks the mean terrain height.

the occurrence of this front. In particular, we inspect relative humidity at $950 \mathrm{hPa}$ (around $500 \mathrm{~m}$ m.s.l.). The front occurs regularly when an undisturbed south-westerly monsoon flow prevails along the coast and further inland. Figure 5 shows the relative humidity at $950 \mathrm{hPa}$ averaged for the 2 months. The front evolves along the coast after noon, which is reflected by a strong gradient in relative humidity between the relatively cool maritime air mass over the Gulf of Guinea and warmer air over land (Fig. 5a). In general, moisture increases from south to north, which is related to strong evaporation over land. Within this large-scale moisture difference a local maximum exists along the front. This is caused by moisture convergence and upward transport of moisture from close to the surface when the monsoon flow decelerates due to surface friction when reaching the coast. During the afternoon, the front is rather stationary, located about $30 \mathrm{~km}$ inland along the coast of eastern Ghana, Togo and western Benin. Further to the east, the front is more diffuse and is located farther away from the coast. After 16:00 UTC, the front starts penetrating inland and reaches SAVE at around 21:00 UTC on the average (Fig. 5b), which agrees well with the conditions of the case study (Figs. 3a, e and 4). During the subsequent hours, the front becomes more diffuse on the average, but continues to propagate inland.

\subsection{First clouds (phase 1)}

During the passage of the front, clouds with low density already form in HILLS (Fig. 2d). Trajectories reveal that air parcels rise by up to $200 \mathrm{~m}$ when following the smoothly rising terrain to the north-east, leading to continuous cooling, an increase of relative humidity and the formation of clouds (Fig. 6a, b). This is in agreement with heat-budget calculations, which reveal that horizontal and vertical cold air advection is responsible for the maintenance of the clouds in HILLS (not shown). This suggests that orographically induced lifting is most important for cloud formation in the north-eastern part of the analysed area. 


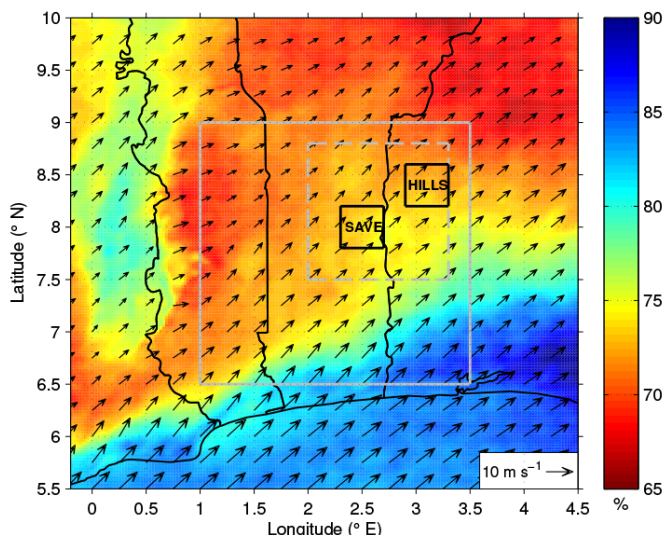

(a)

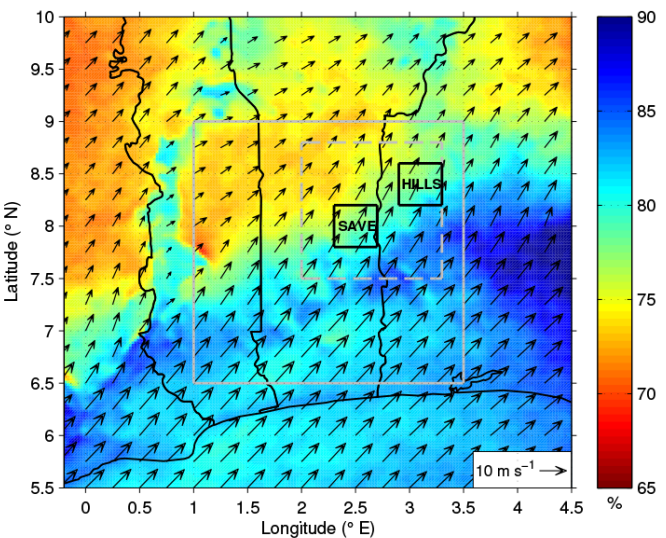

(b)

Figure 5. Spatial distribution of relative humidity (colour-coded) and horizontal wind (arrows) at 950 hPa at 14:00 UTC (a) and 21:00 UTC (b) averaged for the months of July and August 2006. Data are from the $2.8 \mathrm{~km}$ simulation.

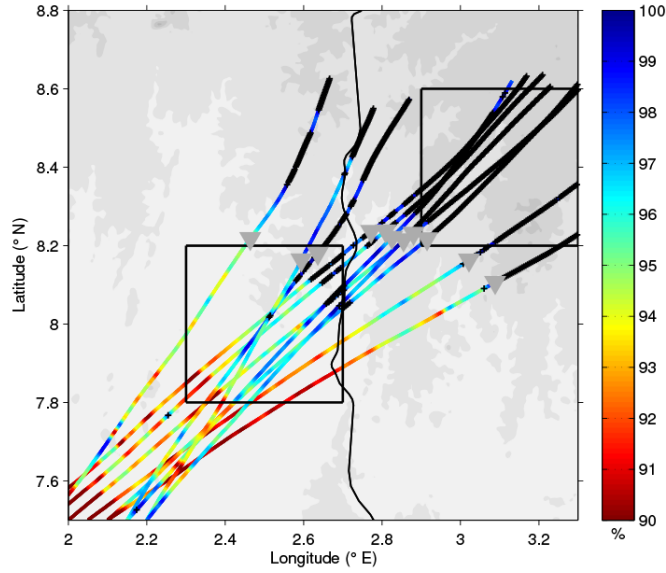

(a)

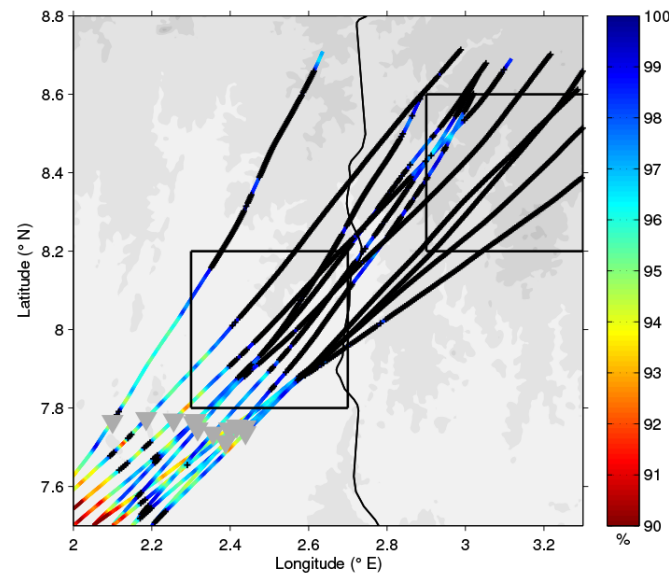

(c)

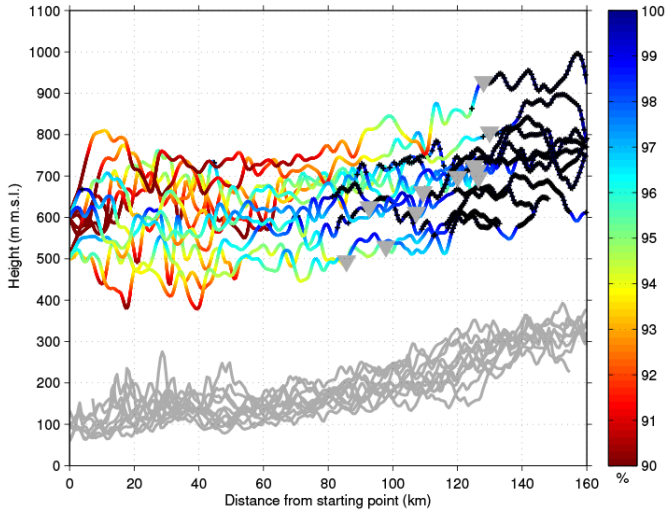

(b)

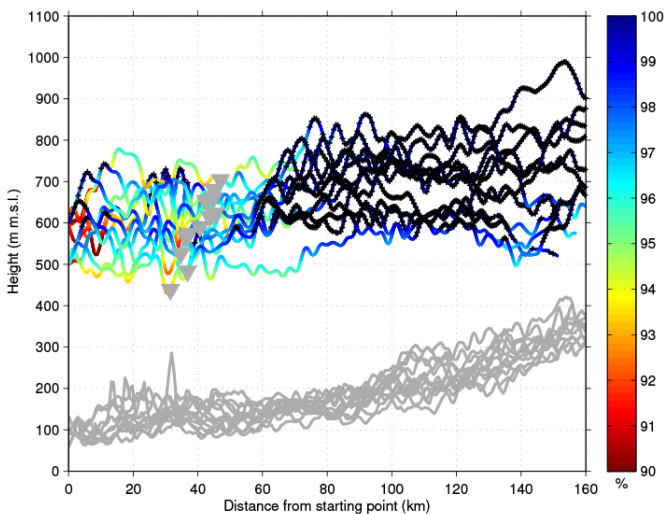

(d)

Figure 6. Relative humidity along trajectories of air parcels started at $7.5^{\circ} \mathrm{N}$ and between 1.9 and $2.2^{\circ} \mathrm{E}$ between 500 and $700 \mathrm{~m}$ m.s.l. at 00:00 UTC (a, b) and at 02:00 UTC (c, d). Black markers indicate non-zero liquid water content and grey triangles indicate the beginning of phase 2 for the respective air parcels. In (a) and (c), the boxes mark SAVE and HILLS, respectively, and terrain height is shown as grey shading with darker colour indicating higher terrain. In (b) and (d), grey lines indicate terrain height along the trajectories. 


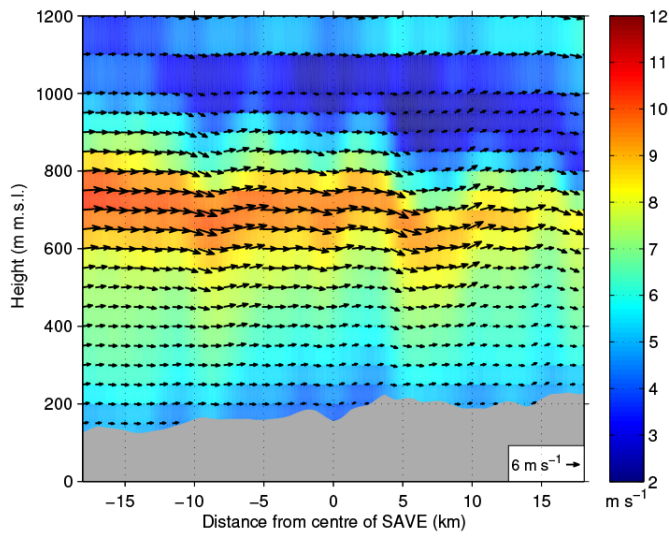

(a)

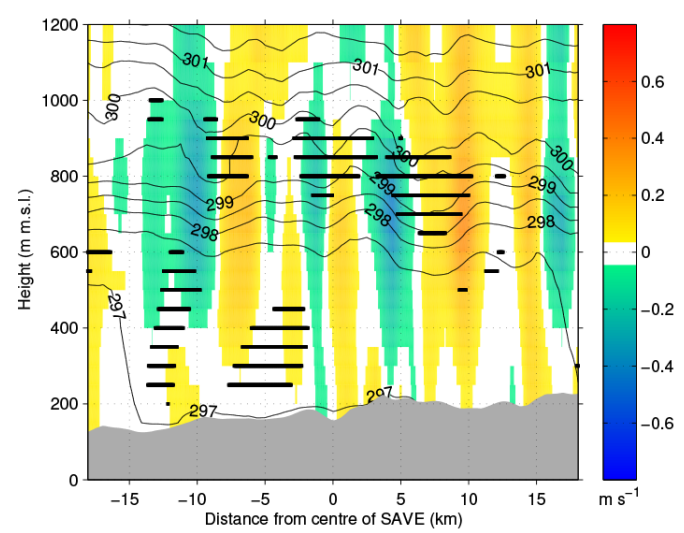

(b)

Figure 7. Vertical cross sections of horizontal wind speed (colour-coded) and flow components (horizontal and vertical (multiplied by 10); arrows) (a) and vertical wind speed (colour-coded) and potential temperature in K (black contours) (b) along a cross section through the centre of SAVE aligned along the mean wind direction of $207^{\circ}$ at 00:00 UTC. The mean wind direction was calculated for the layer below $1000 \mathrm{~m}$ m.s.l. In (b), black horizontal lines show areas with a turbulent kinetic energy higher than $0.5 \mathrm{~m}^{2} \mathrm{~s}^{-2}$. The grey shaded areas mark the terrain height.

Once the front has passed SAVE at around 23:00 UTC, it takes another hour of additional cooling and moistening, mainly between about 550 and $800 \mathrm{~mm}$.s.l. and primarily due to vertical advection, before the first clouds with low density and small vertical extent evolve (Fig. 3). Below this layer, cooling due to horizontal advection persists and weak horizontal dry air advection occurs, which agrees with the general large-scale south-north increase of moisture. Horizontal advection after the passage of the front is largely related to the LLJ, which evolves after 22:00 UTC in SAVE and reaches up to $12 \mathrm{~m} \mathrm{~s}^{-1}$ at around $700 \mathrm{~m} \mathrm{~m}$.s.l. (contours in Fig. 2c). Vertical advection is caused by mean upward motion in SAVE, which transports moist and cool air from below. Besides orographically induced lifting, which is less strong in SAVE than in HILLS due to different terrain gradients, gravity waves indicated by the wavelike structure of the trajectories contribute to the upward motion in the nocturnal atmosphere (Fig. 6). Lifting and cooling cause the highest relative humidity in the wave crests. During phase 1, saturation is reached in wave crests and clouds form in broken band-like structures perpendicular to the mean flow in some regions in the south-western part of the analysed area (Fig. 2a and black markers in Fig. 6c). To further investigate the gravity waves, we produced cross sections through the centre of SAVE of horizontal wind, vertical wind and potential temperature aligned along the mean wind direction (Fig. 7). Gravity waves evolve between about 400 and $1000 \mathrm{~mm}$.s.l. with vertical motion being strongest in the stably stratified layer between around 600 and $800 \mathrm{~mm}$ m.s.l. Fast Fourier transformation reveals a phase lag of roughly $90^{\circ}$ between the waves of potential temperature and vertical wind speed, which is characteristic of gravity waves (Durran, 1990), and dominant wavelengths for both variables ranging between 5 and
$10 \mathrm{~km}$ (not shown). Due to low static stability and/or high wind shear, the Richardson number is smaller than the critical value of 0.25 below and above the height of the LLJ maximum (not shown) and sub-grid-scale turbulence (horizontal lines in Fig. 7b) could contribute to an upward transport of moist and cool air. However, the small residuals of heat and moisture budgets during this phase (Fig. $3 \mathrm{~d}, \mathrm{~h}$ ) suggest that this process is not very effective.

\subsection{Increase of density and spatial expansion of clouds (phase 2)}

As described in Sect. 3, dense extended low-level clouds are confined to the north-eastern part of the analysed area, i.e. downstream of SAVE, during phase 1. After 03:00 UTC, dense clouds suddenly start to form in the south-western part as well and affect SAVE (Fig. 2b, c). We assume that two processes are mainly responsible for this: (i) during phases 0 and 1 , the atmosphere below the clouds is continuously cooled by horizontal advection while vertical cold air advection mainly affects the layer where clouds form (Fig. 3a, b, c). Changes in moisture are small (Fig. 3e, f, g); consequently, relative humidity increases continuously in the respective layer (Fig. 4). (ii) In this environment, enhanced vertical cold air advection leads to the evolution of dense clouds in SAVE, initiating phase 2 (Fig. 3a, c). The enhanced vertical cold air advection is mainly caused by an increase of the mean upward motion (Fig. 8a). This process is also reflected by the trajectories of air parcels started at 02:00 UTC (Fig. 6c, d): air parcels rise by about $100 \mathrm{~m}$ in SAVE (between around 60 and $80 \mathrm{~km}$ from starting point in Fig. 6d), leading to saturation (Fig. 4) and clouds (Figs. 2b, c and 6c, d). This strong rise of trajectories in SAVE does not occur before (Fig. 6a, b). 
The sudden stronger upward motion cannot be caused by gravity waves, because their amplitude and frequency remain about the same. Instead, it is related to a significant increase in horizontal convergence below about $800 \mathrm{~mm}$ m.s.l., i.e. in the lower part of the clouds and below them (Fig. 8b). Horizontal convergence in SAVE is related to a modification in stratification and horizontal wind profiles in areas with dense clouds compared to cloud-free areas: static stability is significantly lower within clouds than at the same level outside the clouds, as is visible along the cross section through the centre of SAVE (Fig. 8c). At the same time, static stability at the cloud top is higher compared to the same level in cloud-free areas. This shift in stratification within the clouds is probably caused by enhanced turbulent kinetic energy (white lines in Fig. 8d), latent heat release due to condensation (positive residual of the temperature budget in the lower part of the cloud layer in Fig. 3d), radiative cooling at cloud top (negative residual of the temperature budget in the upper part of the cloud layer in Fig. 3d) and upward motion in the stably stratified atmosphere (Fig. 8a). The height of the LLJ maximum shifts towards the layer of maximum static stability (Fig. 8d). Consequently, horizontal wind speed increases near cloud top, while it decreases within the clouds. This results in horizontal convergence upstream of the clouds in the layers in the lower part and below the clouds and horizontal divergence in the layer near cloud top (Fig. 8b). When relative humidity has sufficiently increased due to process (i), process (ii) becomes active and triggers new dense clouds upstream of existing ones.

The dense clouds spread to the south-west and at 05:00 UTC, the whole area of SAVE is covered by dense clouds (Figs. 2b, c). This also marks the maximum southwestern extension of dense clouds. The relative humidity is generally lower by several percent south-west of SAVE, which is likely related to the large-scale decrease of moisture from north to south. With an increasing coverage of dense clouds in SAVE - reflected by an increasing averaged liquid water content (Fig. 2c) - horizontal convergence, upward motion and, consequently, vertical cold air advection decrease again in this area (Figs. $3 \mathrm{c}$ and $8 \mathrm{a}, \mathrm{b}$ ). Once the southwestern border of the low-level cloud deck reaches the area with lower relative humidity at around 05:00 UTC, no new clouds are able to form and the clouds slowly dissolve from the south-west and gradually retreat to the north-east. When parts of SAVE become cloud-free at around 06:30 UTC, process (ii) becomes active again with horizontal convergence and upward motion increasing (Fig. 8a, b), and some dense clouds form. However, vertical cold air advection is much weaker than before (Fig. 3c), as the lapse rate in the former cloud layer is reduced due to turbulent mixing, latent heat release, radiative cooling and upward motion. As a consequence, horizontal warm air advection due to inclined isentropes is dominant and causes net warming and a reduction of relative humidity.
A convective boundary layer evolves after sunrise at 06:00 UTC (Fig. 3a, d). When it reaches the bottom of the cloud layer in SAVE at around 08:00 UTC, the cloud base starts to rise and eventually a transition to convective clouds occurs (Fig. 2c).

\section{Discussion}

The processes relevant to cloud formation take place on different scales: the increase of relative humidity due to horizontal cold air advection from the coast is related to the monsoon flow and the LLJ, i.e. to large-scale processes. Clouds are triggered by orographically induced lifting, gravity waves and horizontal convergence upstream of existing clouds, which occur on a scale of a few hundred to a few tenths of kilometres. In addition, turbulent sub-grid-scale mixing is important for the upward shift of the LLJ in cloudy areas. The capability of models to resolve any of these processes, of course, depends on the model-grid spacing. This has to be kept in mind when comparing these results to other studies.

The characteristics of the LLJ as well as the temporal evolution and spatial distribution of the low-level clouds are in general agreement with previous studies: the strength and height of the LLJ are comparable to the LLJ characteristics during cloudy nights reported by Schrage and Fink (2012) and Schuster et al. (2013), considering that the LLJ and cloud base in our simulation are roughly constant in height above sea level. The low-level clouds in the present simulation first form directly upstream of the Oshogbo Hills due to orographically induced lifting and then spread to the south-west, i.e. to the upstream side. The feature is also visible in satellite images (van der Linden et al., 2015), which supports our hypothesis that enhanced upward motion upstream of existing dense clouds triggers new clouds. We find that this process is most relevant to the evolution of dense extended low-level clouds in SAVE. According to our knowledge, this process has not been reported in any region before. In the simulations of Schuster et al. (2013), clouds form upstream of the Oshogbo Hills due to orographically induced lifting and intensify during the night. However, no clear extent to the southwest upstream side can be distinguished. This could be related to the coarser-grid spacing of the model or to different parameterisations. On the one hand, the modification of the horizontal wind field due to the grid-scale clouds is related to model-grid spacing. On the other hand, the upward shift of the layer with maximum static stability and, hence, of the LLJ is at least partly caused by sub-grid-scale turbulent mixing, which depends on the parameterisation in the model. The analysis of the sensitivity of this trigger mechanism to different turbulence parameterisations and grid spacing is beyond the scope of this study, but could be addressed in future studies. 


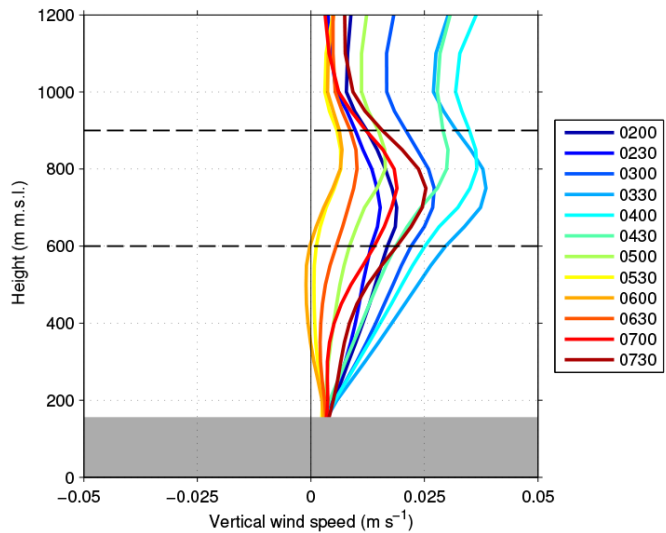

(a)

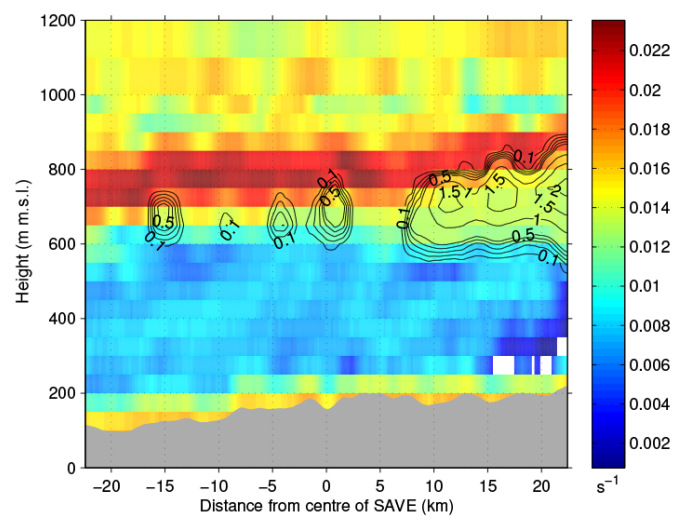

(c)

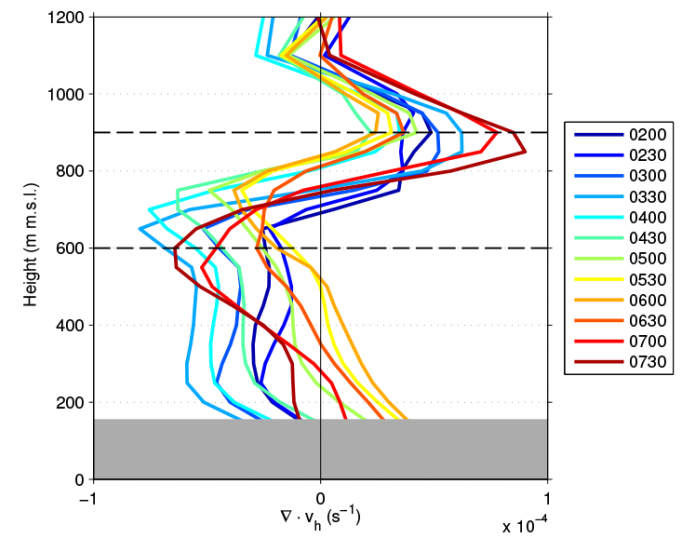

(b)

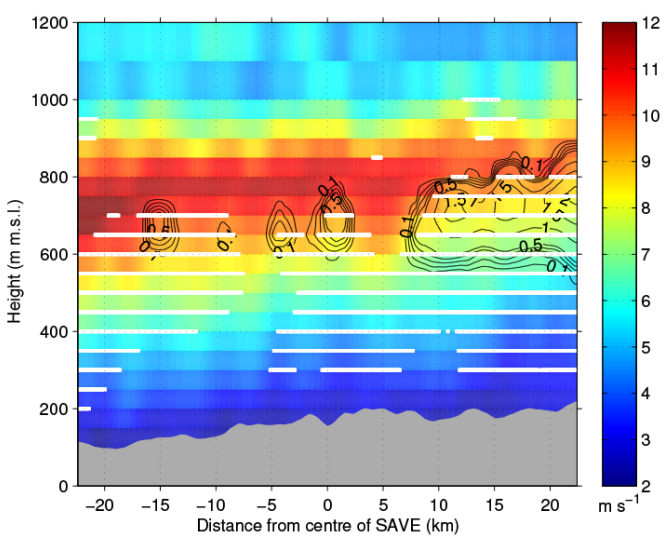

(d)

Figure 8. Profiles of vertical wind speed averaged for SAVE (a) and of horizontal wind divergence calculated for SAVE (b) at different times. Horizontal dashed lines enclose the layer where the liquid water content averaged for the shown period is larger than $0.01 \mathrm{~g} \mathrm{~kg}^{-1}$. Vertical cross section of Brunt-Väisälä frequency (c) and horizontal wind speed (d) along a cross section through the centre of SAVE aligned along the mean wind direction of $223^{\circ}$ at 03:45 UTC. In (c) and (d), the mean wind direction is calculated for the layer below $1000 \mathrm{~m}$ m.s.l. and black contours indicate liquid water content in $\mathrm{g} \mathrm{kg}^{-1}$. In (d), white horizontal lines show grid points with the turbulent kinetic energy higher than $0.5 \mathrm{~m}^{2} \mathrm{~s}^{-2}$. Grey shaded areas mark the terrain height.

Besides the formation of low-level clouds over land upstream of orography, it is found in simulations (Schuster et al., 2013) and satellite observations (van der Linden et al., 2015) that low-level clouds form early along the Guinea Coast and then spread inland. The model-domain size and location in this study do not allow for the study of cloud formation along the coast in detail. Nevertheless, we hypothesise that conditions at the coast and upstream of orography are generally earlier favourable for cloud formation than in other areas over land. In the course of the night, conditions become more favourable in the other areas as well - likely due to horizontal cold air advection and radiative cooling leading to an extent of low-level clouds from the coast to the north as well as to the south-west upstream of orography.

In this simulation, gravity waves in the LLJ layer generate clouds. To exclude that the gravity waves are caused by numerical effects and enter the domain through the boundaries, we performed another model run with a doubled domain size. The southern boundary for this run is located over the Gulf of Guinea. It is evident that the gravity waves are generated over land within the domain and do not enter through the domain borders and travel through the domain. The gravity waves evolve under stable stratification and significant vertical wind shear; i.e. under conditions in which gravity waves are common features (e.g. Fritts et al., 2003; Newsom and Banta, 2003; Wang et al., 2013). Besides vertical wind shear, some of the gravity waves seem to be linked to orographic features, although obstacle heights upstream of SAVE are on the order of $50 \mathrm{~m}$ only.

The front, which exists along the coast of southern West Africa and moves inland in the evening, is a regular feature in the $2.8 \mathrm{~km}$ simulation. As far as we know, it has not been reported before in this region, which is maybe due to a lack of observations or to lacking analysis of high-resolution sim- 
ulations. On the other hand, the formation of a sea breeze in this region was documented by satellite images (e.g. Cautenet and Rosset, 1989) and investigated using observations in Cotonou (Bajamgnigni and Steyn, 2013) and at several stations along the coast of Nigeria (Abayomi et al., 2007). The south-westerly monsoon flow during the wet season often prevents a reversal to offshore flow along the coast of southern West Africa in the evening (Bajamgnigni and Steyn, 2013) and may make the sea breeze indistinguishable from the large-scale flow as known from other regions (overview by Crosman and Horel, 2010). For this reason, we use the term "front" rather than "sea-breeze front" to describe the boundary between the cool maritime and the warm continental air masses, which evolves along the coast during the day. The temporal characteristics of the front, i.e. its stationarity during the day and its inland penetration in the late afternoon and evening, are highly similar to a study by Grams et al. (2010). They investigated a sea-breeze front on the coast of Mauretania, which is stationary during the day and moves several hundred kilometres inland in the evening, and state that the stationarity results from the balance between horizontal advection of cool maritime air and turbulent mixing in the convective boundary layer. When turbulence decays in the evening, the sea-breeze front moves inland. Other authors report cool sea-breeze surges in northern (Garratt and Physick, 1985) and south-eastern Australia (Taylor et al., 2005), which penetrate up to $500 \mathrm{~km}$ inland at nights with moderate onshore flow.

\section{Summary and conclusions}

A high-resolution COSMO simulation was performed for southern West Africa during the monsoon season in order to identify possible controls of the development of nocturnal low-level clouds. The analysis was made in preparation for the DACCIWA field campaign and focuses on the area around the city of Savè (SAVE area), the location of one of the three supersites. The conditions during the case study are typical of nights with an undisturbed south-westerly monsoon flow prevailing in the area of interest.

Based on the simulation data, we hypothesise that several processes are relevant to cloud formation; some of these are illustrated in Fig. 9. A sudden increase of relative humidity occurs in the first half of the night. This is related to a front, which forms along the Guinea Coast during the day between the cool maritime and the warm continental air masses and moves inland in the late afternoon and evening. Subsequent cooling mainly due to horizontal advection with the LLJ and vertical advection results in the formation of clouds. Vertical cold air advection is related to orographically induced lifting (process 1 in Fig. 9) as well as to gravity waves that form in the stably stratified atmosphere around the level of the LLJ (process 2 in Fig. 9). In areas covered by clouds, the height of the LLJ maximum shifts to the top of the clouds, result-

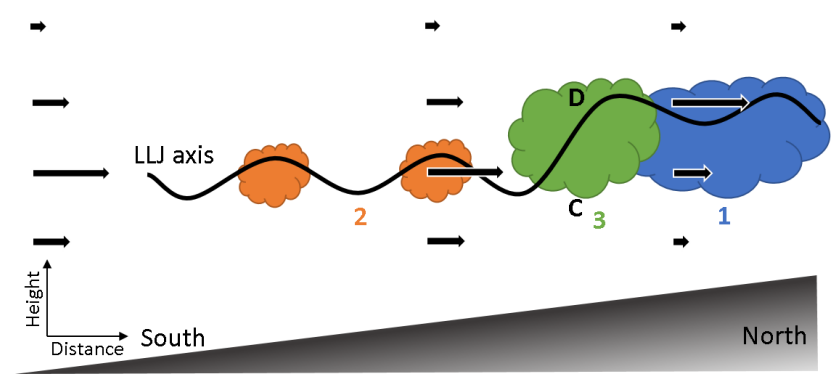

Figure 9. Schematic illustration of the processes contributing to cloud formation, i.e. orographically induced lifting (1), gravity waves (2) and horizontal convergence and upward motion upstream of existing clouds (3). Grey shading marks the terrain, arrows indicate the horizontal flow and the black line illustrates the height of the LLJ axis. C and D mark areas with horizontal convergence and divergence, respectively, related to process 3 .

ing in low-level horizontal convergence and upward motion upstream of the clouds. This triggers new clouds upstream of the existing ones, when saturation is reached (process 3 in Fig. 9). Latent heat release due to condensation and radiative cooling at the cloud top likely contribute to cloud evolution as well, but are not the main mechanisms according to the heat and moisture budgets.

The simulation reveals some interesting processes contributing to the evolution of low-level clouds over southern West Africa, which have not been reported before. The results contributed to an optimised measurement strategy for the DACCIWA field campaign, as they emphasise the importance of measuring advection of heat and moisture, turbulence profiles, vertical motion in the LLJ layer to detect gravity waves and profiles of horizontal wind speed with high temporal and vertical resolution to resolve the structure and evolution of the LLJ. For example, wind profiles were measured using radiosondes, sodars and a wind profiler. Research aircrafts were flying inland from the coast detecting horizontal gradients in, e.g., temperature and moisture. A combination of vertical stare and scanning mode was chosen for a Doppler lidar system to allow for detection of inhomogeneities in wind and backscatter in an area of up to $20 \mathrm{~km} \times 20 \mathrm{~km}$, which could provide evidence for the front, as well as for vertical velocity, which can be used as an indicator for gravity waves and to derive turbulence profiles. The observations will now be used to verify and test the hypotheses for cloud formation gained from this study.

Of course, it is difficult to draw any general conclusions with respect to the representativeness of the processes from this case study. Nevertheless, we think that the processes most likely are also effective in other regions and during other periods, as we chose a night with conditions typical of the monsoon season, and two of the relevant processes gravity waves and triggering of new clouds upstream of existing clouds - are rather independent of local orography. Nevertheless, the sensitivity of cloud formation to factors such as 
orography, geographic location, variations of the LLJ and humidity distribution, model-grid spacing, model-domain size, turbulence parameterisation and aerosol-cloud interactions, which are believed to have a noticeable impact on cloud formation (Knippertz et al., 2015b), was not considered and could be investigated in the framework of the DACCIWA project.

\section{Data availability}

The datasets are available upon request to the corresponding author.

Competing interests. The authors declare that they have no conflict of interest.

Acknowledgement. The research leading to these results has received funding from the European Union 7th Framework Programme (FP7/2007-2013) under grant agreement no. 603502 (EU project DACCIWA - Dynamics-aerosol-chemistry-cloud interactions in West Africa). Special thanks go to Inge Bischoff-Gauß for providing the data of the $2.8 \mathrm{~km}$ simulation and to Fabienne Lohou, Marie Lothon, Cheikh Dione, Peter Knippertz and Andreas Fink for their critical comments and suggestions on the manuscript. Finally, we thank two anonymous referees for their helpful comments.

The article processing charges for this open-access publication were covered by a Research

Centre of the Helmholtz Association.

Edited by: G. Feingold

Reviewed by: two anonymous referees

\section{References}

Abayomi, A. A., Abiodun, B. J., and Omotosho, B. J.: An observational study of sea breeze over Nigerian coastal region, Res. J. Appl. Sci., 2, 745-751, 2007.

Abdou, K., Parker, D. J., Brooks, B., Kalthoff, N., and Lebel, T.: The diurnal cycle of lower boundary-layer wind in the West African monsoon, Q. J. Roy. Meteor. Soc., 136, 66-76, 2010.

Bajamgnigni, A. G. and Steyn, D.: Sea breezes at Cotonou and their interaction with the West African monsoon, Int. J. Climatol., 33, 2889-2899, 2013.

Boutle, I., Finnenkoetter, A., Lock, A., and Wells, H.: The London Model: forecasting fog at $333 \mathrm{~m}$ resolution, Q. J. Roy. Meteor. Soc., 142, 360-371, 2016.

Cautenet, S. and Rosset, R.: Numerical simulation of sea breezes with vertical wind shear during dry season at Cape of Three Points, West Africa, Mon. Weather Rev., 117, 329-339, 1989.

Crosman, E. T. and Horel, J. D.: Sea and lake breezes: a review of numerical studies, Bound.-Lay. Meteorol., 137, 1-29, 2010.

Durran, D. R.: Mountain waves and downslope winds, in: Atmospheric processes over complex terrain, edited by: Blumen, W., vol. 23 of Meteorol. Monographs, 59-81, Amer. Meteorol. Soc., Boston, 1990.

Fiori, E., Parodi, A., and Siccardi, F.: Turbulence closure parameterization and grid spacing effects in simulated supercell storms, J. Atmos. Sci., 67, 3870-3890, 2010.

Fritts, D. C., Nappo, C., Riggin, D. M., Balsley, B. B., Eichinger, W. E., and Newsom, R. K.: Analysis of ducted motions in the stable nocturnal boundary layer during CASES-99, J. Atmos. Sci., 60, 2450-2472, 2003.

Gantner, L., Maurer, V., Kalthoff, N., and Kiseleva, O.: The impact of land-surface parameter conditions and resolution on simulated cloud-topped atmospheric boundary layers, Bound.-Lay. Meteorol., submitted, 2016.

Garratt, J. R. and Physick, W. L.: The inland boundary layer at low latitudes: II sea-breeze influences, Bound.-Lay. Meteorol., 33, 209-231, 1985

Grams, C., Jones, S., Marsham, J., Parker, D., Haywood, J., and Heuveline, V.: The Atlantic inflow to the Saharan heat low: observations and modelling, Q. J. Roy. Meteor. Soc., 136, 125-140, 2010.

Herzog, H.-J., Vogel, G., and Schubert, U.: LLM-a nonhydrostatic model applied to high-resolving simulations of turbulent fluxes over heterogeneous terrain, Theor. Appl. Climatol., 73, 67-86, 2002.

Kalthoff, N., Träumner, K., Adler, B., Späth, S., Behrendt, A., Wieser, A., Handwerker, J., Madonna, F., and Wulfmeyer, V.: Dry and moist convection in the boundary layer over the Black Forest - a combined analysis of in situ and remote sensing data, Meteorol. Z., 22, 445-461, 2013.

Knippertz, P., Fink, A. H., Schuster, R., Trentmann, J., Schrage, J. M., and Yorke, C.: Ultra-low clouds over the southern West African monsoon region, Geophys. Res. Lett., 38, doi:10.1029/2011GL049278, 2011.

Knippertz, P., Coe, H., Chiu, J. C., Evans, M. J., Fink, A. H., Kalthoff, N., Liousse, C., Mari, C., Allan, R. P., Brooks, B., , Danour, S., Flamant, C., Oluwagbemiga, O. J., Lohou, F., and Marsham, J. H.: The DACCIWA project: Dynamics-aerosolchemistry-cloud interactions in West Africa, B. Am. Meteorol. Soc., 96, 1451-1460, 2015a.

Knippertz, P., Evans, M. J., Field, P. R., Fink, A. H., Liousse, C., and Marsham, J. H.: The possible role of local air pollution in climate change in West Africa, Nature Climate Change, 5, 815822, 2015b.

Lothon, M., Saïd, F., Lohou, F., and Campistron, B.: Observation of the diurnal cycle in the low troposphere of West Africa, Mon. Weather Rev., 136, 3477-3500, 2008.

Maurer, V., Bischoff-Gauß, I., Kalthoff, N., Gantner, L., Roca, R., and Panitz, H.-J.: Initiation of deep convection in the Sahel in a convection-permitting climate simulation for northern Africa, Q J. Roy. Meteor. Soc., doi:10.1002/qj.2966, accepted, 2016.

Miltenberger, A. K., Pfahl, S., and Wernli, H.: An online trajectory module (version 1.0) for the nonhydrostatic numerical weather prediction model COSMO, Geosci. Model Dev., 6, 1989-2004, doi:10.5194/gmd-6-1989-2013, 2013.

Newsom, R. K. and Banta, R. M.: Shear-flow instability in the stable nocturnal boundary layer as observed by Doppler lidar during CASES-99, J. Atmos. Sci., 60, 16-33, 2003.

Parker, D., Burton, R., Diongue-Niang, A., Ellis, R., Felton, M., Taylor, C., Thorncroft, C., Bessemoulin, P., and Tompkins, A.: 
The diurnal cycle of the West African monsoon circulation, Q. J. Roy. Meteor. Soc., 131, 2839-2860, 2005.

Ritter, B. and Geleyn, J.-F.: A comprehensive radiation scheme for numerical weather prediction models with potential applications in climate simulations, Mon. Weather Rev., 120, 303-325, 1992.

Schättler, U., Doms, G., and Schraff, C.: A Description of the Nonhydrostatic Regional COSMO-Model Part VII : User's Guide, Tech. rep., Deutscher Wetterdienst, P.O. Box 100465, 63004 Offenbach, Germany, available at: http://www.cosmo-model.org (last access: 23 October 2015), 2014.

Schrage, J. M. and Fink, A. H.: Nocturnal continental low-level stratus over tropical West Africa: observations and possible mechanisms controlling its onset, Mon. Weather Rev., 140, 1794-1809, 2012.

Schuster, R., Fink, A. H., and Knippertz, P.: Formation and maintenance of nocturnal low-level stratus over the southern West African monsoon region during AMMA 2006, J. Atmos. Sci., 70, 2337-2355, 2013.
Taylor, J. R., Kossmann, M., Low, D. J., and Zawar-Reza, P.: Summertime easterly surges in southeastern Australia: a case study of thermally forced flow, Aust. Meteorol. Mag., 54, 213-223, 2005. van der Linden, R., Fink, A. H., and Redl, R.: Satellite-based climatology of low-level continental clouds in southern West Africa during the summer monsoon season, J. Geophys. Res., 120, 1186-1201, 2015.

Wang, Y., Creegan, E., Felton, M., Ligon, D., and Huynh, G.: Investigation of nocturnal low-level jet-generated gravity waves over Oklahoma City during morning boundary layer transition period using Doppler wind lidar data, J. Appl. Remote Sens., 7, 073487, doi:10.1117/1.JRS.7.073487, 2013. 